\title{
Nominal juxtaposition in Australian languages: An LFG analysis ${ }^{1}$
}

\author{
LOUISA SADLER \\ Department of Language and Linguistics, University of Essex \\ RACHEL NORDLINGER \\ School of Languages and Linguistics, The University of Melbourne
}

(Received I5 May 2007; revised I9 April 2009)

It is well known that Australian languages make heavy use of nominal juxtaposition in a wide variety of functions, but there is little discussion in the theoretical literature of how such juxtapositions should be analysed. We discuss a range of data from Australian languages illustrating how multiple nominals share a single grammatical function within the clause. We argue that such constructions should be treated syntactically as set-valued grammatical functions in Lexical-Functional Grammar (LFG). Sets as values for functions are well-established in LFG and are used in the representation of adjuncts, and also in the representation of coordination. In many Australian languages, coordination is expressed asyndetically, that is, by nominal juxtaposition with no overt coordinator at all. We argue that the syntactic similarity of all juxtaposed constructions (ranging from coordination through a number of more appositional relations) motivates an analysis in which they are treated similarly in the syntax, but suitably distinguished in the semantics. We show how this can be achieved within LFG, providing a unified treatment of the syntax of juxtaposition in Australian languages and showing how the interface to the semantics can be quite straightforwardly defined in the modular LFG approach.

\section{INTRODUCTION}

Australian languages, like many of the world's languages (Haspelmath 2004), frequently express nominal coordination with an asyndetic construction in which the coordinated nominals are simply juxtaposed. Nominal

[I] This paper results from joint research into coordination strategies in Australian Aboriginal languages funded by a British Academy grant (SG-39545). Earlier versions of this work have been presented at the ALSo5 Conference in Melbourne, 2005, and the LFGo6 conference in Konstanz, 2006. We thank both audiences for helpful feedback that has led to substantial improvements in the presentation and argumentation, and we are also grateful to two anonymous $J L$ referees for comments and to Avery Andrews, Doug Arnold, Brett Baker and Mary Dalrymple for comments and discussion. Of course, we remain responsible for remaining errors and inadequacies. 
juxtaposition is also used in many of these Australian languages to express a wide range of other, non-coordinated construction types (see e.g. Blake 1987), including pronoun-noun appositions, part-whole constructions, genericspecific constructions and inclusory constructions, to be exemplified below. Juxtaposed nominal structures in Australian languages have received very little attention in the theoretical literature, yet they raise many interesting issues for syntactic analysis. In particular, the fact that such a range of coordinated and non-coordinated construction types are found with the same surface syntax has implications for many standard syntactic analyses which would assume that coordinations have a distinct syntactic structure from other nominal-nominal combinations, such as approaches postulating a CoordP for coordinate structures (Progovac 1997, Johannessen 1998) for example. In this paper we provide an analysis of the full range of nominal juxtapositions in Australian languages within Lexical-Functional Grammar (LFG), an analysis which exploits the flexible architecture of LFG to capture the syntactic similarities of the various juxtaposed nominal constructions while allowing them to be suitably distinguished in the mapping to the semantics. On the view that we explore, the surface similarity between coordination and a whole range of other construction types which are expressed by means of juxtaposition motivates a similar treatment for each of these construction types in the syntax. Our analysis builds on the standard LFG approach to coordination (Kaplan \& Maxwell I988, Dalrymple \& Kaplan 2000, Dalrymple 200I), in which coordinated NPs are treated as set-valued grammatical functions at f-structure. We argue that non-coordinated juxtapositions, in which multiple nominals in juxtaposition share a single grammatical function in the clause, should likewise be treated as sets at $\mathrm{f}$-structure, thus providing a unified analysis of a range of nominal juxtapositions common to many Australian languages. The differences between the various construction types are captured by distinguishing between them in the mapping to the semantics, which we discuss in some detail in section 5. Our modular approach, which differentiates syntactically between different types of nominal juxtaposition only in so far as such differentiation is overtly justified, provides a natural and unified account of nominal juxtaposition in Australian languages.

The paper is structured as follows. In section 2 we introduce a range of construction types which are widely and productively expressed by means of nominal juxtaposition in some Australian languages. Section 3 outlines the LFG approach to the syntax of coordination, which will form the basis of our syntactic account of nominal juxtapositions in Australian languages. Section 4 shows how this approach can straightforwardly account for asyndetic coordination structures and extends this syntactic analysis to account for the syntax of other juxtaposed nominal structures in Australian languages as well, providing both a natural account of these constructions and a unified account of juxtaposition in Australian languages. In section 5 
we outline the semantics which differentiates these different construction types. Section 6 shows how a possibility inherent to our account of nominal juxtaposed structures provides for a straightforward account of inclusory constructions, and section 7 concludes.

\section{JUXTAPOSED NOMINAL CONSTRUCTIONS}

The most common way to encode nominal coordination in Australian languages is through juxtaposition, whereby the coordinated nominals are simply listed with no particular marker of their coordinated status (I)-(6). The fact that such phrases have a conjunctive interpretation is shown by the form of elements which agree with the construction as a whole; for example, the coreferential pronouns in (3) and (4) and the verbal agreement marker in (5) and (6) pick up the RESOLVED number feature. ${ }^{2}$

(I) Niya kurrka-tha barruntha-ya wuran-ki nguku-y 3SG(NOM) take-ACT yesterday-LOC food-MLOC water-MLOC 'Yesterday he took (with him) food and water.'

(2) Gaj-ba ngurru manganyma yangaji

(Evans 1995: 250 Kayardild) eat-FUT IPL.INC(NP) tucker(ACC) meat(ACC) 'Let's eat the bread and meat.' (Nordlinger 1998a: 257 Wambaya)

(3) Paanth thono pam pul mimp katp-r woman one(NOM) man(NOM) 3DU(NOM) cloth(ACC) grasp-NP 'A woman and a man are holding up a piece of cloth.'

(Gaby 2006: 3I8 Kuuk Thaayorre)

(4) Dathin-a maku-wa bithiin-da bi-l-da warra-j that-NOM woman-NOM man-NOM 3-PL-NOM go-ACT 'Those men and women are going.' (Evans 1995: 249 Kayardild)

(5) Ngayirni babi-rni ngiji-nginyi-nu kujkarrana ISG.ERG older.brother-ERG see-IDU.EX-did two(M) yaminju-nu, nyu-rruku nyinawarra shooting.star-did 2SG-went this.way 'My brother and I saw two shooting stars when you'd gone.'

(Pensalfini 2003: I78 Jingulu)

[2] The abbreviations used in the examples are: A 'transitive subject'; ABS 'absolutive'; ACC 'accusative'; ACT 'actual'; APASS 'antipassive'; ASS 'associative'; CON 'continuous'; DAT 'dative'; DU 'dual'; ERG 'ergative'; EX 'exclusive'; F 'feminine'; FUT 'future'; IMP 'imperative'; IMPF 'imperfective aspect'; INC 'inclusive'; INCH 'inchoative'; LOC 'locative'; M 'masculine'; MLOC 'modal locative'; MPROP 'modal proprietive'; NEUT 'neuter'; NM 'nominaliser'; NOM 'nominative'; NON-SING 'non-singular'; NP 'non-past'; P 'past'; P.IPFV 'past imperfective'; PL 'plural'; POT 'potential'; P.PFV 'past perfective'; PRES 'present'; PROP 'proprietive'; PURP 'purposive'; RDP 'reduplicated'; RECIP 'reciprocal'; SG 'singular'; SUB 'subject'; TWD 'directions towards'; VEG 'vegetable'. 
(6) Pala-nga ngatu jarri-nya-pinti-ngi, mima-nikinyi-yi

that-LOC stationary INCH-NM-ASS-LOC wait.for-IMPF-3PL.SUB

puluku, kujarra kangkuru-jirri waraja yalapara

3DU.DAT two kangaroo-DU one goanna

'And there, on the finishing line, the two kangaroos and one goanna waited for those two.'

(Sharp 2004: 315 Nyangumarta)

Consistent with the 'free word order' properties typical of many of these languages (Hale 1983, Simpson I99I, Nordlinger I998b, Austin 200I), such coordinations can also be discontinuous in some languages, as shown in (7) and (8) (compare these with the contiguous example from Kuuk Thaayorre in (3)). ${ }^{3}$

(7) Ngul ngay kirk kempthe kal-m thul=yuk

then ISG(ERG) spear(ACC) apart carry-P.IPFV woomera(ACC) $=$ STUFF 'I used to carry spears and woomeras separately.'

(Gaby 2006: 320 Kuuk Thaayorre)

(8) Nganip-n ngancn yik-nhat nganam-un

father-DAT IPL.EX(NOM) say-P.PFV mother-DAT

'We said to Dad and Mum.' (Gaby 2006: 320 Kuuk Thaayorre)

In addition to coordination, Australian languages are characterised by extensive use of nominal juxtaposition, exhibiting a substantial amount of flexibility as to how such nominal sequences are to be interpreted semantically (Blake 1987, 200I; Dixon 2002). For example, many Australian languages make use of both generic-specific constructions and part-whole constructions in which two nominals are placed in syntactic juxtaposition and jointly determine the referent of the syntactic argument. Below we provide examples from a selection of languages - Kalkatungu, Kayardild and Yidiny - illustrating the use of juxtaposition to encode generic-specific and part-whole constructions, both across languages and within a single language. (9)-(I4) illustrate generic-specific constructions.

(9) tjaa maa wartatji

this vegetable.food orange

'the/this orange'

(Blake 200I : 4I8 Kalkatungu)

[3] Of course, it is possible that these are afterthought constructions; however, Gaby (2006) does not describe them as having the sorts of intonational properties that would suggest such an analysis. It is more straightforward to show that such discontinuous examples are truly coordinated in languages with verbal agreement, given the presence of resolved agreement on the verb. See (40) below for an example of this sort.

The possibility of discontinuous coordination is only mentioned in a subset of grammatical descriptions and thus we can't provide discontinuous examples from all of the languages exemplified above. It is not known whether the lack of discussion reflects the fact that discontinuous coordination is not possible in these languages, or whether the examples are sufficiently infrequent that they just didn't arise in the corpora on which the descriptions are based. In any event, it is clear that an analysis of coordination in Australian languages needs to be able to account for the possibility of discontinuous coordination in at least some languages. 
(Io) Ngayika ati-ntji ari-li thuwarr-ku

I meat-DAT eat-APAss snake-DAT

'I'm eating snake.'

(II)
Dathin-a dangka-a niya
that-NOM man-NOM
wanku-ya
3SG(NOM) spear-PROP
wumburung-kuru raa-ja
elasmobranch-MLOC shark-MLOC
'That man speared a shark with a spear.' ${ }^{4}$

(Blake 200I : 4I9 Kalkatungu)

(Evans 1995: 244 Kayardild)

(I2) Dathin-a jardi-wuthin-da badi-ja jul-i wuran-ki that-NOM mob-PLENTY-NOM carry-ACT bone-MLOC food-MLOC

'All those (ants) are carrying a bone.' (Evans 1995: 244 Kayardild)

(I3) Gana mayi jimirr jula:lin

TRY vegetable(ABS) yam(ABS) dig:GOING.IMP

'Go and try to dig some yams up!'5

(I4) bama mula:rri wulnggainy bana:

(Dixon I977: 247 Yidiny)

person(ABS) initiated.man(ABS) cover:PAST water:LOC

'The initiated men were drowned by the (rising) water.'

(Dixon I977: 247 Yidiny)

In all of these examples we find a 'generic' nominal (e.g. 'vegetable food', 'meat', 'person') combined with a 'specific' nominal (e.g. 'orange', 'snake', 'initiated man') to JOINTLY determine the reference of the NP as a whole. The appropriate English equivalent of these generic-specific constructions is really a single referential NP, as per the translation provided. These constructions, therefore, are not equivalent to non-restrictive appositional constructions in English such as 'I am eating meat, namely snake', or 'I saw the elasmobranch, namely the shark', in which one single nominal specifies or defines the reference and the other provides elaboration. Nor are they equivalent to such English constructions in discourse or pragmatic terms. Rather, the joint use of both nominals is, in these languages, a pragmatically neutral way to encode reference. See Wilkins (2000) for further discussion of this point in relation to the Australian data.

Part-whole juxtapositions operate similarly, as shown by the following examples :

(I5) ngida wamburra

tree trunk

'tree trunk'

(Evans I995: 248 Kayardild)

[4] The term elasmobranch refers to fish with a cartilaginous skeleton, such as sharks and rays.

[5] The Yidiny examples in this paper have been rewritten in a standard practical orthography which marks dental sounds with ' $h$ ', uses ' $j$ ' for a palatal stop and ' $r r$ ' for an alveolar trill, and 'ng' for a velar nasal. 
(i6) dangkaa ngabaya

person spirit

'person's spirit'

(I7) jugi gubu gana ngayu wanggi wawa:lna

(Evans I995: 248 Kayardild)

tree(ABS) leaf(ABS) TRY I(NOM) up look:PURP

'I must try to look up at the leaves on the trees.'

(Dixon I977: 248 Yidiny)

In the above examples of the part-whole construction we find juxtaposed nominals each bearing the same case marking, realising (part of) the same grammatical function, and jointly picking out the relevant referent for the NP as a whole.

In addition to generic-specific and part-whole constructions, nominal juxtapostion is very common in expressing a number of other construction types in which multiple nominals and pronouns are strung together in a single clause, jointly determining a single referent or having overlapping reference. Examples include the following: ${ }^{6}$

(I8) Garidi-ni bungmanyi-ni gin-amany yanybi

husband-ERG old.man-ERG 3SG.M.A-P.TWD get

'(Her) old man husband came and got (her).'

(Nordlinger I998a: I33 Wambaya)

(i9) Pam-al ith nhul may carrots yakakerr

man-ERG that 3SG.ERG VEG carrots cut:RDP:P.PFV

'The man cut up the carrots.'

(Gaby 2006: 290 Kuuk Thaayorre)

(20) Nhani mankada nhintha pani

3SG.F(NOM) girl(ABS) shame none

'The girl is shameless.' (Austin I98I: I02 Diyari)

(2I) yingu bama bunya bindam galiny

this(ABS) person(ABS) woman(ABS) 'name'(ABS) go:PAST

'This woman Bindam went.' (Dixon 1977: 252 Yidiny)

(22) dathin-a dangka-a niya wirdi-j

that-NOM fellow-NOM $3 \mathrm{SG}(\mathrm{NOM})$ remain-ACT

'That fellow (Kajurku) was waiting.' (Evans I995: 278 Kayardild)

In (I8)-(22) we again find strings of nominals and/or pronouns jointly expressing reference to a single entity (or single group of entities). All of these constructions, including the generic-specific and part-whole constructions exemplified above, are often described as 'appositional' in the Australianist literature (Heath I978, I984; Blake I979, I983, I987, 200I; Evans I995), where

[6] Note that in none of the examples from Kuuk Thaayorre (19), Diyari (20) or Kayardild (22) is the pronoun grammatically required in the clause. 
apposition is used in its broadest sense, as in the following traditional definition of this term (Crystal 1997: 24):

apposition: A traditional term retained in some models of GRAMMATICAL description for a sequence of units which are CONSTITUENTS at the same grammatical LEVEL, and which have an identity or similarity of REFERENCE.

Examples such as (I8) and (I9) illustrate two straightforward variants of Australian-style 'appositional' constructions - a nominal-nominal appositional construction in (I8), in which 'old man' is juxtaposed with 'husband' in subject function, ${ }^{7}$ and a nominal-pronominal appositional construction in (I9), in which the nominal elements 'man' and 'that' are juxtaposed with the coreferential third person pronoun $n h u l .{ }^{8}$ The use of such nominal appositions or juxtapositions is considerably less marked than appositional constructions in English (as in 'Her husband, the old man, came and got her', cf. (I8)), and are usually best translated with simple non-apposed structures (e.g. 'The man cut up the carrots' in (I9) and not 'He, the man, cut up vegetables, being carrots'). ${ }^{9}$ More generally, it is important to realise that the Australianist use of the term 'apposition' should not be taken to imply that these constructions are to be viewed as equivalent to the sorts of nonrestrictive constructions often referred to as appositions in English.

Given the wide range of uses to which the term 'apposition' has been put in the literature, a terminological aside is important here to clarify our use of the term in this paper (and in the Australianist literature more generally). Note that we generally seek to avoid this particular terminological minefield in the present paper by using the more neutral term 'nominal juxtaposition' to describe the syntax of these constructions.

In the general literature on apposition a distinction is commonly drawn between restrictive and non-restrictive apposition (e.g. Quirk et al. 1985), also known as close vs. loose apposition (e.g. Lekakou \& Szendröi 2007). Consider the pair of examples below. In (23a) the two terms of the apposition, Burns and the poet, serve jointly to determine the reference of the NP. The expression Burns itself does not pick out a unique entity; the restrictive phrase in a close (or restrictive) apposition restricts the denotation so that a unique referent is picked out. In (23b), on the other hand, Burns picks out a unique individual and the expression the poet makes a comment or provides further information about this individual. In English (and other languages) a

[7] Note that the two apposed nominals come before the auxiliary gin-amany here, showing them to jointly belong to an NP constituent since the Wambaya auxiliary must always be the second constituent in the clause (Nordlinger 1998a).

[8] Note also in passing that (I9) additionally exemplifies a generic-specific in 'vegetable', 'carrot'.

[9] See Stirling (2008) for a discussion of the role that such 'double-reference' plays in Kala Lagaw Ya narratives. 
loose apposition is set off intonationally, while in a close apposition the two elements consitute a single intonational unit.

\section{(23) (a) Burns the poet (close) \\ (b) Burns, the poet (loose)}

There is an extensive body of literature which explores this distinction in a range of languages and different formal frameworks. Much of the syntactic discussion concerning non-restrictive, or loose, appositions has centered on non-restrictive relative clauses, and on whether the relative clause is integrated syntactically, and if so, how or at what level. The 'radical orphanage' approach (Fabb I990, Espinal I99I, Peterson 2004) takes the non-restrictive modifier to be not integrated into the syntactic structure of the matrix at all, whereas integrated approaches generally take non-restrictive relative clauses to be adjoined to the nominal (Jackendoff I977, Kempson 2003, Arnold 2004, 2007). Amongst the properties of loose or non-restrictive appositions which both integrated and non-integrated accounts have sought to accommodate are a range of interpretational facts: for example, loose appositions appear to escape the scope of sentence negation and that of propositional verbs. The (integrated) approach of Potts $(2003,2005)$ captures this by putting the semantic content of (loose) appositional material in a separate dimension from which it is not accessible to the normal propositional content.

Although the prevalent use of the term apposition in the literature on European languages is to refer to non-restrictive nominal, clausal or other phrases (loose appositions), there has also been work on the nature of close or restrictive apposition and how it relates to modifier-head constructions both syntactically and semantically (Acuña-Fariña I999; Keizer 2005, 2007; Lekakou \& Szendröi 2007). ${ }^{\mathbf{1 0}}$

This is an area which has been very little explored in Australianist work. It is clear from a look through a number of grammatical descriptions that there are examples which strongly suggest a close (restrictive) interpretation, but that equally, there are examples in which one nominal is set off from the sentence or phrase intonationally, suggestive of a loose or non-restrictive apposition. Unfortunately, however, the Australianist literature provides

[Io] Lekakou \& Szendröi (2007) provide an approach to the Greek polydefinite construction which they model on their approach to close apposition. They argue that both Greek polydefinites (as in (i), from Lekakou \& Szendröi 2007: I4I) and close appositions are multiply headed and jointly determine the denotation of the NP, essentially by intersection.

(i) (a) $\mathrm{o}$ aetos to puli

the eagle the bird

(b) to puli o aetos the bird the eagle 
almost no discussion of how these types of appositions may differ syntactically. ${ }^{11}$ In this paper, we restrict ourselves to examples of close appositions, such as the examples provided above, which we take to introduce semantic content which is integrated into the truth-conditional semantics. Our use of the term 'apposition' (or indeed nominal juxtaposition) should also be interpreted as referring to close appositions only.

Returning now to the Australian language data, a further type of juxtaposed construction common in Australian languages is the inclusory construction (Singer 200I, 2005) (also known in the literature as the "plural pronoun construction', Schwartz I988a), in which a plural pronoun referring to the superset is combined with a subset nominal. In many languages the inclusory construction involves simple juxtaposition of the two elements, as in the following example from Kayardild:

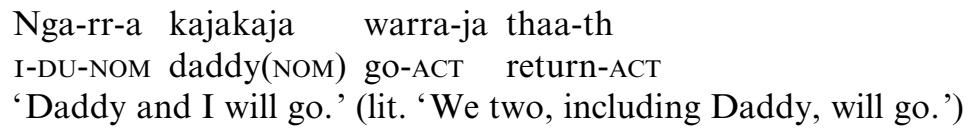

(Evans 1995: 249 Kayardild)

Although inclusory constructions have much in common with the other juxtaposed constructions above, they differ in that the agreement features of the construction as a whole are those of only one of the constituent parts - namely the superset pronoun. We return to a discussion of inclusory constructions and their relationship to other juxtaposed constructions in section 6 .

Thus, across Australian languages we find juxtaposed nominal constructions used with a range of functions beyond coordination, including generic-specific constructions, part-whole constructions, inclusory constructions and various types of nominal-nominal 'appositions'. While the specific construction types and their properties can vary across different languages, the general phenomenon whereby sequences of nominals can have multiple interpretations including coordinated and non-coordinated meanings is pervasive among Australian languages and is frequently referred to in the literature as a common characteristic of Australian languages in general (e.g. Blake 1987). Indeed, some researchers have gone so far as to claim for particular Australian languages that they have no noun phrases at all, with all nominals existing in apposition (in the broad sense of the term). This is the analysis given by Blake (1983) for Kalkatungu, for example, and by Heath (1978: 52) for Ngandi, in which 'noun phrases which have more than one constituent are typically formed by apposition'. Even languages with clear NP structures for head-modifier relations also have a range of

[II] For relevant discussion however, see Hale (I98I), Nash (I986), Simpson (I99I) on 'merged' vs. 'unmerged' interpretations of nominals in Warlpiri. 
constructions in which nominals are seemingly juxtaposed without any evidence of syntactic asymmetry. For example, Evans (1995: 247), in discussing the Kayardild constructions exemplified in (II) and (I5) above, states that 'there are no syntactic reasons for considering one nominal to be the head, and it is better to treat them as apposed nominals'.

Significantly, all of these juxtaposed construction types share the syntactic properties of the asyndetic coordinated constructions in that neither nominal can be clearly identified as the head of the phrase. Evans (I995), for example, treats both nominals in the generic-specific and part-whole constructions as filling the 'head' slot in the NP structure (p. 235). He argues explicitly that the constructions are double-headed, on the grounds that either noun can function alone as the head of an NP so that there is no syntactic dependency, and because the nouns may appear in either order (pp. 244-248). Similar arguments have been made for analogous constructions in other Australian languages such as Kuuk Thaayorre (Gaby 2006: 283), Kalkatungu (Blake I983) and Mparntwe Arrernte (Wilkins 2000). ${ }^{12}$

Indeed, the only clear formal difference between coordinated constructions and other juxtapositions is that the former show resolved agreement on the verb (in languages with verbal agreement) whereas the latter do not. ${ }^{13}$ This difference arises from the fact that the two nominals in a coordinated construction establish distinct referents, whereas the two nominals in other types of juxtapositions combine to identify a single referent. Consider, for example, the Wambaya example (25) below, repeated from (18). The fact that the auxiliary (gin-amany) shows singular number agreement forces the interpretation of the juxtaposed nominals as describing the same referent. If the auxiliary had dual number agreement here (gurl-amany), the NP would be interpreted as a coordination (i.e. '(her) husband and the old man').

$$
\begin{aligned}
& \text { Garidi-ni bungmanyi-ni gin-amany yanybi } \\
& \text { husband-ERG old.man-ERG 3SG.M.A-P.TWD get } \\
& \text { '(Her) old man husband came and got (her).' }
\end{aligned}
$$

(Nordlinger 1998a: I33 Wambaya)

Note that verbal agreement in languages like English similarly disambiguates between true coordination and so-called boolean coordination in examples such as My wife and the mother of my children is/are singing. We return to a discussion of boolean coordination in section 7 . Of course in both

[I2] Note, however, that some analyses of inclusory constructions in languages with verbal agreement morphology, argue that the superset pronoun should be analysed as the head of the construction, since it is the features of this pronoun that show up as agreement on the verb.

[I3] Note that there may well be intonational differences between the various construction types also, but detailed empirical evidence for this is not currently available. 
the Wambaya and the English cases, verbal agreement cannot disambiguate if both elements are themselves plural.

Apart from this semantically motivated difference (concerning the agreement features), all of these types of juxtaposed constructions-coordinations, generic-specific constructions, part-whole constructions, inclusory constructions and other types of nominal-nominal appositions - have the same basic syntactic structure in that they consist of a sequence of two nominals fulfilling the same grammatical function, neither of which is syntactically dependent upon the other. In fact, they all satisfy a broad definition of coordination, such as the following from Haspelmath (2007: I):

The term coordination refers to syntactic constructions in which two or more units of the same type are combined into a larger unit and still have the same semantic relations with other surrounding elements.

This suggests that the appropriate analysis for all of these juxtaposed nominal constructions is as a multiply-headed structure in the syntax, in which each element is independently fulfilling the same grammatical function in parallel, similar to the analysis usually assumed for coordination (see Blake I983: I7I-I72 for a proposal along similar lines). In the following sections we will sketch out such an analysis in LFG and show how it provides an explanatory account of the Australian language data. We begin with a discussion of the standard treatment of coordination in LFG.

\section{LFG ANALYSIS OF COORDINATION}

LFG is a lexicalist constraint-based syntactic framework which posits two co-present levels of syntactic representation: c-structure, which encodes phrase structural relations (of precedence and dominance) between elements, and f-structure, which represents a level of internal syntactic structure based on grammatical functions, modelling predicate argument relations. C-structures are represented by phrase structure trees of a familiar sort while $\mathrm{f}$-structures are represented by attribute value matrices. C-structures and f-structures (corresponding to a given string) are interrelated by means of a mapping function $\phi$, which places elements of c-structure (in the domain of the function) in correspondence with f-structures. The mapping is expressed by means of equations (or f-descriptions) associated with lexical items and phrase structure nodes (phrase structure rules in LFG are annotated with such equations). The relation between c-structure and f-structure is many-to-one and into (f-structures can arise which are not related to specific c-structure nodes, and more than one c-structure node can correspond to a single f-structure). F-structures are subject to well-formedness constraints, notably those of completeness and coherence, which ensure that all and only the arguments of a predicate are present (as values of subcategorisable grammatical functions) in the f-structure projected by a predicate. For 
comprehensive introductions to the formalism see Bresnan (200I), Dalrymple (200I) and Falk (200I).

This approach provides a highly modular and flexible framework for syntactic description: in particular, it has proved sufficiently flexible to be an appropriate tool for modelling the syntax of widely divergent languages ranging from the highly configurational to the radically non-configurational. A significant body of work has developed LFG analyses of phenomena in Australian Aboriginal languages (Simpson \& Bresnan I983, Simpson I99I, Austin \& Bresnan I996, Nordlinger I998b, Wilson I999).

A simple sentence such as (26) would have the f-structure (27). F-structures are simple attribute-value matrixes, where values can be atomic or complex. A particular feature of LFG is the use of sets as values of attributes (that is, the value of the attribute is a set of f-structures), as in the case of the grammatical function ADJunct in (27), alongside atomic and complex-valued features (TENSE and SUBJ respectively in (27)).

(26) Kim wept yesterday.

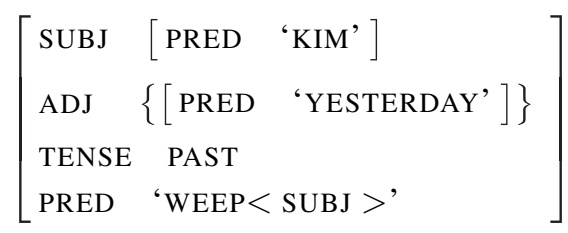

When a property is asserted to hold of a set, its behaviour with respect to the set will depend on the nature of the particular property. The majority of properties are distributive: such a feature is an attribute of every member of the set. The grammatical functions are distributive; thus Kim is the sUBJ of both the f-structure of shout and the f-structure of cry in the (set of) f-structures for Kim shouted and cried. As we will see below, agreement features and the CONJFORM feature are non-distributive: when a feature is non-distributive, it and its value are a property of the set as a whole.

A standard analysis of NP coordination in LFG (Dalrymple \& Kaplan 2000, Dalrymple 200I) assumes a c-structure coordination schema along the lines of (28) in which each coordinand is defined as belonging to a set-valued f-structure as specified by the annotation $\downarrow \in \uparrow . .^{14}$

$$
\begin{aligned}
& \mathrm{NP} \rightarrow \mathrm{NP} \quad \mathrm{CONJ} \quad \mathrm{NP} \\
& \downarrow \in \uparrow \quad \uparrow=\downarrow \quad \downarrow \in \uparrow
\end{aligned}
$$

[I4] This is an instance of a more general coordination scheme which combines like constituents, phrasal or lexical. 
The representation of a coordinate structure involves a hybrid object, that is, a set which additionally may itself have properties (the non-distributive properties referred to above) alongside the elements or members of the set. Consider the representation of (29), given in (30):

(29) John and I met.

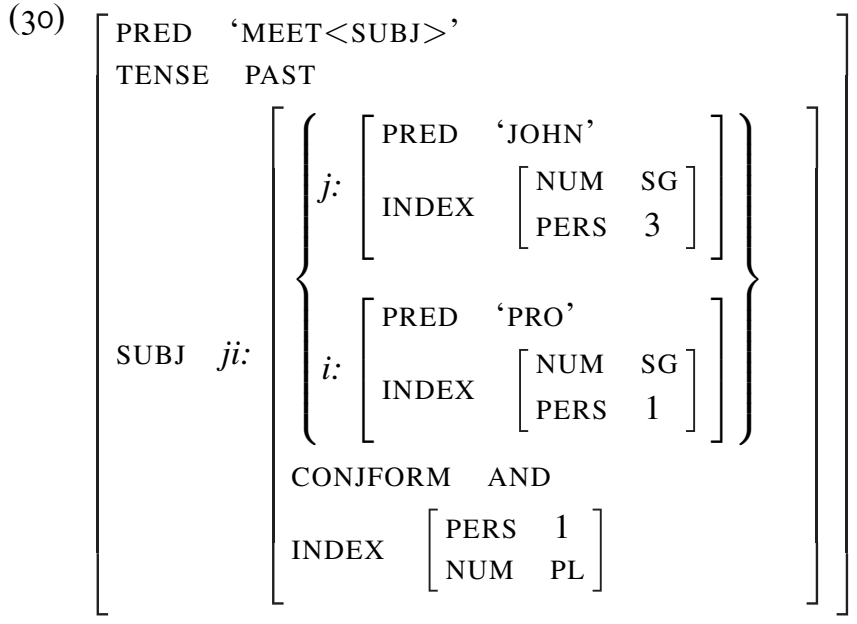

In (30), each conjunct contributes an f-structure (labelled $j$ and $i$ in (30)) to the set of f-structures which is the value of the subJ attribute. Additionally, the sUBJ (labelled $j i$ ) has some features which express properties of the set as a whole - in this example, the feature CONJFORM with the value AND and the INDEX feature which expresses the person/number/gender (PNG) agreement features of the coordinate structure as a whole (as noted above, agreement features are taken to be non-distributive).

A common pattern of agreement with coordinate NPs involves SYNTACTIC RESOLUTION, whereby the agreement features of all the conjuncts are taken into account in 'calculating' the agreement features of the coordinate structure as a whole. Dalrymple \& Kaplan (2000) develop an approach to syntactic feature resolution using set-valued agreement features and the simple operation of set union. Thus, for example, if PERs features are represented as shown in (3I), set union gives the standard resolution pattern for this feature. ${ }^{15}$ Features such as CONJFORM and INDEX are non-distributive

[I5] An exclusive first person is encoded as $\{\mathrm{S}\}$ - see Dalrymple \& Kaplan (2000) for a discussion of the Fula system. 
(i.e. resolving) while most features, including grammatical functions such as SUBJ and OBJ, as already noted, are distributive. ${ }^{16}$

$$
\begin{aligned}
\{\mathrm{S}, \mathrm{H}\}(\mathrm{IST}) \cup\{\mathrm{H}\}(2 \mathrm{ND}) & =\{\mathrm{S}, \mathrm{H}\}(\mathrm{IST}) \\
\{\mathrm{S}, \mathrm{H}\}(\mathrm{IST}) \cup\{\}(3 \mathrm{RD}) & =\{\mathrm{S}, \mathrm{H}\}(\mathrm{IST}) \\
\{\mathrm{H}\}(2 \mathrm{ND}) \cup\{\}(3 \mathrm{RD}) & =\{\mathrm{H}\}(2 \mathrm{ND}) \\
\{\}(3 \mathrm{RD}) \cup\{\}(3 \mathrm{RD}) & =\{\}(3 \mathrm{RD})
\end{aligned}
$$

Similarly, a two-gender (M, F) system with resolution to the masculine works as follows (with MASC corresponding to the set $\{\mathrm{M}\}$ and FEM to the empty set):

$$
\begin{aligned}
\{\mathrm{M}\}(\mathrm{MASC}) \cup\{\mathrm{M}\}(\mathrm{MASC}) & =\{\mathrm{M}\}(\mathrm{MASC}) \\
\{\mathrm{M}\}(\mathrm{MASC}) \cup\{\}(\text { FEM }) & =\{\mathrm{M}\} \text { (MASC) } \\
\{\}(\text { FEM }) \cup\{\}(\text { FEM }) & =\{\}(\text { FEM) }
\end{aligned}
$$

As shown in (33), the coordination schema for NP coordination in a language with syntactic feature resolution involves simple f-descriptions which ensure that the PERS and GEND features of each NP conjunct are a subset of the PERS and GEND features of the whole set (in the following, IND abbreviates INDEX). ${ }^{17}$

$$
\begin{aligned}
& \mathrm{NP} \rightarrow \\
& \text { NP } \\
& \downarrow \in \uparrow \\
& (\downarrow \text { IND PRES }) \subseteq(\uparrow \text { IND PRES }) \\
& \downarrow=\uparrow \quad \downarrow \in \uparrow \\
& (\downarrow \text { IND GEND }) \subseteq(\uparrow \text { IND GEND }) \\
& (\downarrow \text { IND PRES }) \subseteq(\uparrow \text { IND PRES }) \\
& (\downarrow \text { IND GEND }) \subseteq(\uparrow \text { IND GEND })
\end{aligned}
$$

Resolution of the NUM feature, on the other hand, is not purely syntactic, as shown by the mimimally contrasting examples in (34), to which we return briefly in section 7 .

(34) (a) The president and chief executive are attending the meeting in Beirut.

(b) The president and chief executive is attending the meeting in Beirut.

In LFG it is possible to associate a collection of f-descriptions (or equations) with a name in a template definition. The rule schema can then call the template (a template call is denoted in the formalism by the symbol @). This simple and convenient abbreviatory device has a number of useful properties.

[16] The types of features are defined as follows (Dalrymple \& Kaplan 2000):

For any distributive property $P$ and set $s, P(s)$ iff $\forall f \in s . P(f)$.

For any nondistributive property $P$ and set $s, P(s)$ iff $P$ holds of $s$ itself.

[17] The original formulation of syntactic resolution in Dalrymple \& Kaplan 2000 does not refer to INDEX but simply to the individual PERS and GEND agreement features. Since then, a distinction between two sets of agreement features, INDEX and CONCORD, has been postulated (see King \& Dalrymple 2004). We have updated the treatment of syntactic resolution here to be consistent with this later work. See further note 24 below. 
For example, because templates can call other templates, they can be organised to express linguistic generalisations succinctly (see Dalrymple et al. (2004) for further discussion). The PERS and GEND equations for NP coordination can be expressed in a template:

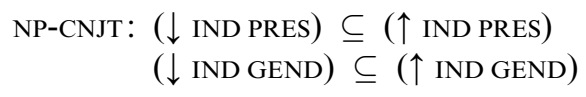

We can therefore represent (33) more simply as in (36), in which each NP has been associated with the coordination template in (35):

$$
\begin{aligned}
& \mathrm{NP} \rightarrow \quad \mathrm{NP} \quad \mathrm{CONJ} \quad \mathrm{NP} \\
& \downarrow \in \uparrow \quad \uparrow=\downarrow \quad \downarrow \in \uparrow \\
& \text { @NP-CNJT @NP-CNJT }
\end{aligned}
$$

\section{Modelling nominal Juxtaposition}

In this section we show how the general LFG approach to coordination described above can be built upon to account for the full range of juxtaposed nominal constructions in Australian languages, discussed in section 2. We first show how the basic syntactic analysis of coordination can be extended to account for asyndetic coordination (section 4.I) and other non-coordinated juxtaposed constructions (section 4.2). We argue that these constructions can all be treated as essentially the same at f-structure, with the differences between them captured in the mapping to the semantics. A preliminary semantic treatment of some of the construction types is provided in section $5 .^{18}$

\section{I Juxtaposition as asyndetic coordination}

As we saw in section 2, NP coordination in Australian languages is frequently encoded by juxtaposition, without any explicit marker of coordination. It seems reasonable to assume that such coordinate structures receive precisely the same syntactic treatment as (29) above, so that they differ in the presence (or absence) of a coordinator. This suggests the c-structure schema in (37) for asyndetic nominal coordination. In (37) X is a categorial metavariable ranging over $\mathrm{N}$ and $\mathrm{NP} ;{ }^{19}$ otherwise it differs from

[18] Note, however, that nothing in our analysis hinges on the particular semantic analysis provided. In fact, the modularity of the LFG approach means that it is possible to use the same general glue approach to attach whatever semantic analysis one desires to a given syntactic structure.

[19] In the languages which we are concerned with, it is generally possible for 'bare' Ns to consititute full NPs on their own, and to be associated with referential NP meanings. As a 
the standard schema in (36) above in lacking a coNJ feature. ${ }^{20} \mathrm{We}$ defer full discussion of the agreement constraints (for the non-distributive INDEX features) to section 5, but assume for the moment that the agreement template NP-CNJT is associated with each daughter node, just as in (36).

$$
\begin{aligned}
& x \rightarrow x \quad x \\
& \downarrow \in \uparrow \quad \downarrow \in \uparrow \\
& \text { @NP-CNJT @NP-CNJT }
\end{aligned}
$$

The f-structure corresponding to the coordinated subject in (6) (repeated here as (38)) is then that in (39), with resolved INDEX features but no CONJ feature in the outer f-structure.

(38) Pala-nga ngatu jarri-nya-pinti-ngi, mima-nikinyi-yi that-LOC stationary INCH-NM-ASS-LOC wait.for-IMPF-3PL.SUB puluku, kujarra kangkuru-jirri waraja yalapara 3DU.DAT two kangaroo-DU one goanna 'And there, on the finishing line, the two kangaroos and one goanna waited for those two.'

(Sharp 2004: 315 Nyangumarta)

$$
\left[\left\{\begin{array}{l}
{\left[\begin{array}{ll}
\text { INDEX } & \left.\begin{array}{ll}
\text { PERS } & 3 \\
\text { NUM } & \text { PL }
\end{array}\right] \\
\text { INDEX } & {\left[\begin{array}{ll}
\text { NUM } & \text { SG } \\
\text { PERS } & 3
\end{array}\right]}
\end{array}\right]} \\
{\left[\begin{array}{ll}
\text { PRED } & \text { 'KANGAROO' } \\
\text { INDEX } & {\left[\begin{array}{ll}
\text { NUM } & \text { DUAL } \\
\text { PERS } & 3
\end{array}\right]}
\end{array}\right]}
\end{array}\right]\right.
$$

Recall from section 2 that coordination structures can be discontinuous, as in the following examples. That these are truly coordinations (and not afterthoughts, for example) is readily established by such things as discourse context (Blake 200I) and the fact that the verb shows resolved agreement, as in (40).

consequence, it is often impossible to tell whether coordination has taken place at the phrasal or the lexical level, and both are certainly possible. In some cases, the presence of a demonstrative will sometimes make clear the level at which elements are juxtaposed.

[20] A reviewer raises the possibility of instead considering the coordinator to be null. While this is certainly possible, we do not see that it has any advantage over the analysis presented here, and in any case, LFG eschews the use of zero forms unless they are independently required (see, for example Bresnan 200I for discussion). 
(40) Kintja-(ng)ku=yana intji-mi-ngi-yu ntiya-(ng)ku female-ERG $=$ and pelt-FUT-me-they.DU stone-ERG tjipa-yi kurlayingu-thu this-ERG male-ERG

'The girl and boy will both pelt me with stones.'

(4I) Ngul ngay kirk kempthe kal-m thul=yuk then ISG(ERG) spear(ACC) apart carry-P.IPFV woomera(ACC) $=$ STUFF 'I used to carry spears and woomeras separately.'

(Gaby 2006: 320 Kuuk Thaayorre)

Our analysis combines straightforwardly with the standard approach to discontinuity and non-configurationality in LFG to account for these cases. In LFG c-structure nodes are generally optional - by the Principle of Economy, only those nodes which are motivated by overt lexical material (or by some semantic requirement) are present (Bresnan 200I).

In an example like (4I) the two parts of the coordinate structure appear separated by the verb and its modifier: each is represented at c-structure as an instance of the coordinate structure schema (37) with just one daughter (42).

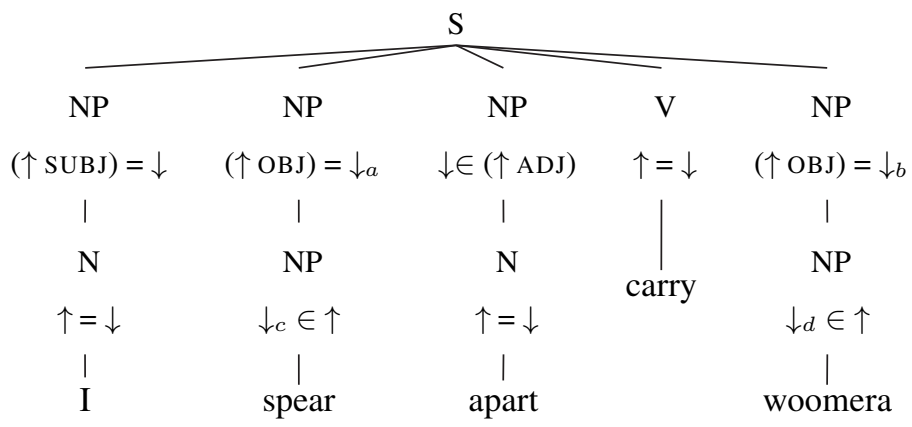

In non-configurational structures, the grammatical functions to be assigned to an element of c-structure are not identified in configurational terms but by morphological means. In the example at hand, it is the case marking on the nominals which indicates the SUBJ (marked ERG) and the (discontinuous) OBJ (marked ACC). Since in principle a wide range of different grammatical function assignments might be compatible with a string of categories we assume NPs under S are freely annotated with the equation $(\uparrow \mathrm{GF})=\downarrow$, where GF is a meta-variable over the relevant set of grammatical functions. It is the case markers which identify which grammatical function a nominal element maps to (Simpson 1991, Austin \& Bresnan 1996, Nordlinger 1998b).

The two ACC-marked NPs under S will both independently co-specify the OBJ f-structure (as shown by the labels $a$ and $b$ in (42)), and hence they both contribute elements to the (coordinate) set. 


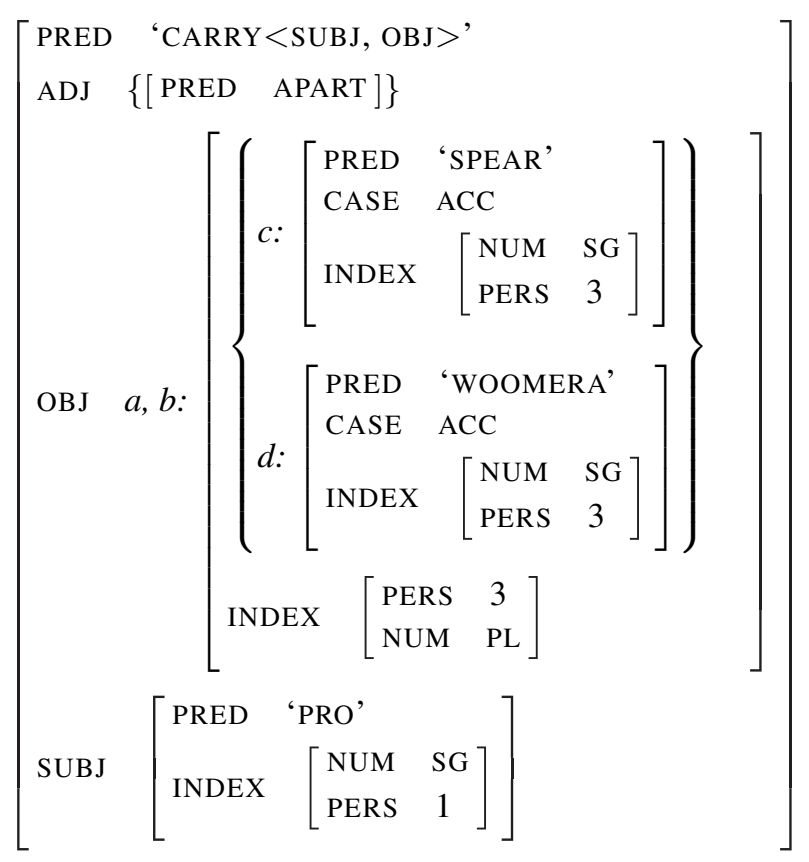

If we choose to associate some other functional annotation with the ACCmarked NPs (treating one or both of them as contributing the whole оBJ function, for example), no complete and coherent f-structure would be produced. Our analysis of asyndetic coordination thus extends to account straightforwardly for the possibility of discontinuous coordinations in these languages.

\subsection{Juxtaposition beyond coordination: a common syntax}

In section 2 we saw that many Australian languages use nominal juxtaposition to encode a range of non-coordinated construction types, including generic-specific, part-whole, and nominal-pronoun appositions. These constructions show the same syntactic properties as asyndetic coordination: the juxtaposed nominals do not stand in a syntactic dependency relation with one another and they fulfill the same grammatical function. Our proposal is that the full range of nominal juxtapositions discussed in section 2 all have the same surface syntax, and thus should be given the same syntactic analysis (apart from the non-distributive agreement features) - namely, as hybrid structures at f-structure. We are therefore arguing that the LFG analysis of coordination be extended to these other juxtaposed constructions also, with the differences between the construction types captured in the mapping to the semantics. Not only does this approach provide a unified account of nominal juxtaposition in Australian languages - both coordinated and noncoordinated - but representation of non-coordinated juxtaposed nominals 
as members of a set directly captures the intuition expressed by many researchers that these nominals are co-heads (e.g. Blake 1983, Evans 1995, Wilkins 2000, Gaby 2006). ${ }^{21}$

On our analysis, the f-structure corresponding to the nominal juxtaposition in (I8), repeated in (44), is as in (45). Apart from the value of the non-distributive (INDEX) features of the set (which we discuss below), the f-structure in (45) is structurally identical to that associated with a coordination such as (39) repeated as (46).

(44) Garidi-ni bungmanyi-ni gin-amany yanybi

husband-ERG old.man-ERG 3SG.M.A-P.TWD get

'(Her) old man husband came and got (her).'

\section{(45) Apposition:}

(Nordlinger 1998a: I33 Wambaya)

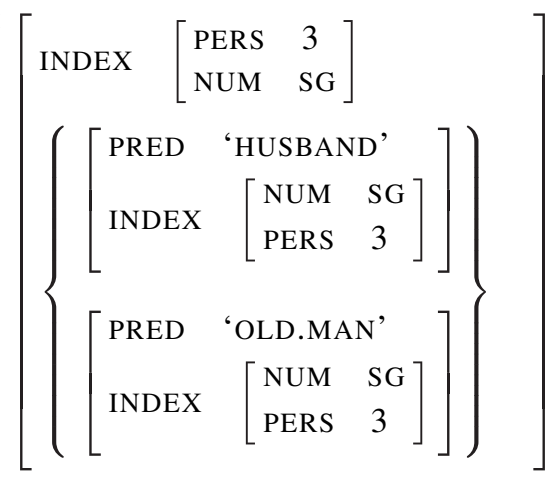

(46) Coordination:

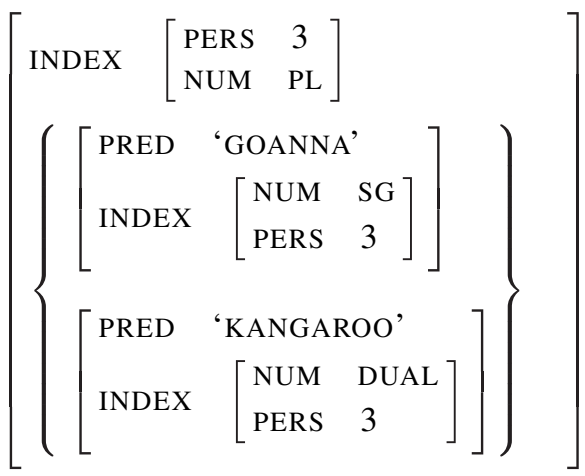

[2I] The observation that apposition and coordination may be syntactically similar is not, of course, new: it is also found in the literature on languages such as English, for example Quirk et al. (I985), Meyer (1992) and de Vries (2006). Meyer observes that 'while there are clear semantic differences between the two relations [i.e. apposition and coordination - LS \& RN], syntactically the relations are quite similar' (Meyer 1992: 45). Exploring the relationship of juxtaposition in Australian Aboriginal languages to e.g. apposition in configurational Indo-European languages is, of course, well beyond the scope of the present paper, and we make no claims about these very different languages. 
This analysis directly reflects the fact that there is no visible syntactic distinction within the nominal strings themselves between nominal coordination and other types of nominal juxtaposition. ${ }^{22}$ In fact, as discussed in section 2 above, the nominal phrase in (44) is itself ambiguous between a coordinate and an appositional interpretation, disambiguated only by the verbal morphology. The auxiliary form gin-amany '3SG.M.A-P.TWD' determines that the SUBJ is ${ }_{3} \mathrm{SG}$. If this example meant 'the old man and her husband (they) ...' then the finite auxiliary would be encoded with ${ }_{3} \mathrm{DU}$. Crucially, the formal differences lie only in the agreement features of the set; there is no visible syntactic distinction within the nominal structure itself. Thus, as far as the syntax is concerned, our analysis needs to be able to account for the fact that the same nominal f-structure may sometimes involve feature resolution (i.e. in a coordination structure), and sometimes not (i.e. in an appositional structure).

Thus, we propose that both appositional and coordinate constructions are licensed by the basic phrase structure schema in (47), with differences arising in terms of the overall agreement features of the structures and in the semantics, as we shall soon see. Appositional and coordinate structures differ syntactically, on this view, purely in terms of the overall agreement features of the structure as a whole. Structurally, they are identical.

$$
\begin{aligned}
& x \rightarrow x \quad x \\
& \downarrow \in \uparrow \quad \downarrow \in \uparrow
\end{aligned}
$$

Recall from section 3 above that feature resolution in coordination structures is licensed by the NP-CNJT template, repeated here from (35), which is associated with each NP in the coordinated phrase:

$$
\begin{aligned}
\text { NP-CNJT: } & (\downarrow \text { IND PRES }) \subseteq(\uparrow \text { IND PRES }) \\
& (\downarrow \text { IND GEND }) \subseteq(\uparrow \text { IND GEND })
\end{aligned}
$$

In non-coordinated juxtapositions such as (44), on the other hand, the juxtaposed constituents are co-referential and there is no feature resolution at the level of the set: the features of the set are the same as the features of each of the members. Thus, in our terms, these constructions generally involve INDEX sharing between the set and the members of the set. We define the 'appositional' template in (49), which is associated with each of the daughter constituents in the above phrase structure rule in a non-coordinated juxtaposed construction, as in (50). ${ }^{23}$ This template ensures that the INDEX

[22] Note that we are concerned here only with the lack of syntactic differences. There may well be intonational or other differences between the two construction types and, as we discuss in section 5 , there are of course clear semantic differences.

[23] Recall that we use the term 'appositional' in a broad sense here, to mean simply sequences of juxtaposed elements having the same grammatical function and similar or overlapping reference. 
features of each daughter constituent are shared with the INDEX features of the set (i.e. a set containing two 3SG daughters will likewise have 3SG INDEX features).

$$
\begin{aligned}
& \text { NP-APPOS: }(\downarrow \text { IND })=(\uparrow \text { IND }) \\
& x \rightarrow x \quad x \\
& \uparrow \in \downarrow \quad \uparrow \in \downarrow \\
& \text { @NP-APPOS@NP-APPOS }
\end{aligned}
$$

Thus, the only structural difference between the coordinated phrase in (5I) and the non-coordinated phrase in (52), both repeated from above, is that the two members of the coordinated phrase are associated with the NP-CNJT template (as in (37)), and the two members of the non-coordinated phrase are associated with the NP-APPOS template (as in (50)), resulting in different INDEX features for the set as a whole. In all other respects, the two are structurally identical. $^{24}$

[24] In the interests of clarity, we assume here that all INDEX features in appositional constructions will be shared between the members and the set. This is potentially an oversimplification, since it may well be the case that there will be instances of appositions in which the f-structures may differ in one or more INDEX features despite being descriptions of the same real-world entity. A circumstance where this might arise is where apparent person mismatches are allowed in appositional structures (e.g. in the English 'us linguists', 'you children'). Another difficult issue arises with part-whole constructions such as 'woman feet', where there may be a mismatch between the number of the part and the number of the whole. A further tricky area concerns gender. Here a complicating factor in the interpretation of appositional data is the proposal in the literature that nouns have both INDEX GEND features (usually relevant to phenomena such as predicate-argument agreement) and CONCORD GEND features (potentially relevant to agreement within a NP, that is, cases of head-modifier agreement), and these may not match (Wechsler \& Zlatiæ 2003, King \& Dalrymple 2004). Well-known cases of 'mismatch' nouns include the Serbo-Croatian collective nouns of the second declension, such as deca 'children', which are analysed by Wechsler \& Zlatiæ (2003) as FEM.SG CONCORD but NEUT.PL INDEX. The potential for nonmatching between CONCORD and INDEX in GEND complicates the interpretation of putative mismatches in appositional structures in the languages we are concerned with, because of course such examples may involve nouns differing in CONCORD GEND but not in INDEX GEND. Other cases of gender mismatch in appositional constructions could potentially arise from generic-specific constructions in which hyponyms and hypernyms clearly belong to different gender classes (e.g. VEGetable and NEUTer); we leave investigation of whether this occurs to further research. In sum, very little is known about gender agreement in the languages we are concerned with, noris the relevance of the distinction between INDEX and CONCORD features yet established for these languages. Should plausible examples of gender mismatch emerge, the constructions at issue could be captured by modifying the above analysis in a number of ways. One possibility would be to have only one daughter in the appositional phrase structure rule contribute INDEX features to the set (i.e. be associated with the NPAPPOS template above), with the INDEX features of the other daughter only partially shared, or not shared at all. See the discussion of inclusory constructions in section 6 for an example of how this might work. 
(5I) Pala-nga ngatu jarri-nya-pinti-ngi, mima-nikinyi-yi that-LOC stationary INCH-NM-ASS-LOC wait.for-IMPF-3PL.SUB puluku, kujarra kangkuru-jirri waraja yalapara 3DU.DAT two kangaroo-Du one goanna 'And there, on the finishing line, the two kangaroos and one goanna waited for those two.'

(Sharp 2004: 3I5 Nyangumarta)

(52) Garidi-ni bungmanyi-ni gin-amany yanybi

husband-ERG old.man-ERG 3SG.M.A-P.TWD get

'(Her) old man husband came and got (her).'

(Nordlinger I998a: I33 Wambaya)

Finally, note that all of the non-coordinated juxtaposed construction types (generic-specfic, nominal-pronoun, etc.) can be also discontinuous, as exemplified with the generic-specific construction in (53).

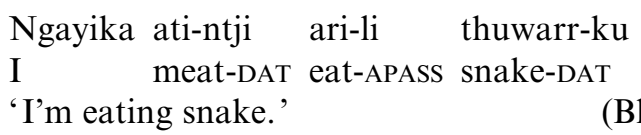

(Blake 200I: 4I8 Kalkatungu)

This will follow directly from the analysis of discontinuous coordinate constructions discussed in section 3 above. Namely we assume that each element in the c-structure rule is optional, under the Principle of Economy of Expression (Bresnan 200I: 9I), thereby allowing each nominal to constitute an NP on its own in the c-structure, while still contributing to a set at f-structure.

\section{Computing meAnings: SEMANTIC COMPOSITION}

We have argued that both coordinated and non-coordinated juxtapositions are rightfully analysed as structurally identical, with the syntactic differences lying only in the relationship between the INDEX features of the set and those of the member elements, and in the mapping to the semantics. In this section we present a semantic analysis of some of these construction types and show how it integrates with the syntactic analysis presented above. We show how it is possible in LFG to adopt a single syntax and distinguish the construction types in the mapping to the semantics. Our focus is not so much on the details of the semantic analysis per se, about which much more could be said, but rather on the interface itself. ${ }^{25}$

[25] As we note above, nothing in our analysis hinges on the particular details of the semantic analysis presented here. Our general aim is to show how a single syntactic structure can be associated with different semantics. 


\section{I Coordinate meanings}

As we have seen, nominal juxtapositions can have coordinate meanings, involving syntactic feature resolution and the construction of a coordinate semantics. Coordinate agreement can be captured in the template (35), repeated below as (54), following Dalrymple \& Kaplan (2000); this will suffice for present purposes as our focus is not on the details of agreement. ${ }^{26}$ This template is associated with each constituent in the phrase structure rule, as in (55), where we have coordinate readings.

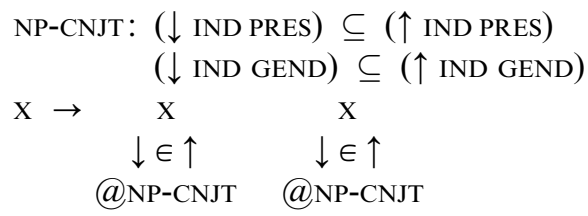

We turn now to the semantics, and in particular to semantic composition, that is, how meanings are associated with (and derived from) the syntactic structures we are discussing. It is generally assumed in LFG that semantic composition involves reference to f-structures, that is, to representations of syntactic predicate-argument structure, rather than to c-structures. Thus despite the widely varying c-structures that languages have, their semantics is largely invariant, in that the same sorts of meanings are encoded by a diverse range of external syntactic structures. ${ }^{27}$

The predominant approach to semantic composition in LFG, which we adopt here, uses linear logic for meaning assembly. The meanings themselves will generally be represented as simple predicate logic expressions. These can be viewed as an abbreviatory shorthand for more elaborate meaning expressions. Our focus here is primarily on the process of meaning assembly, that is, how meanings are associated with syntactic structures, and in particular on the syntax-semantics interface.

In the glue (linear logic) theory of semantic composition, instructions for combining meanings are stated as premises in a logical deduction. The order of composition is therefore determined only as the logic itself determines it

[26] Many Australian languages distinguish four or more genders (e.g. M, F, NEUT, VEG) and exhibit defaults and underspecification in gender agreement, and thus interesting issues can arise in the formulation of the details of gender resolution and gender agreement in such languages. For an approach to gender using complex GEND features rather than set-valued features, see Dalrymple et al. (2007).

[27] Of course, this is not to deny that other sources of linguistic information, or other types of linguistic structure, are relevant to the process of semantic composition and interpretation. The modular correspondence-based architecture of LFG allows non-syntactic levels of representation such as prosodic structure and information structure (which models discourse relations) to provide important information guiding semantic interpretation. Constraints arising through multiple projections may combine to determine the meaning of a given utterance. 
(and thus details of syntactic structure, such as the phrasal composition, are not important). A crucial aspect of the use of glue, or linear logic, for meaning assembly is its resource sensitivity: once a premise is used, it is used up and no longer available for subsequent steps in the deduction. The approach is therefore motivated by the observed resource sensitivity of natural language interpretation. A highly accessible introduction to meaning composition in LFG is provided by Dalrymple (200I: chapter 9), on which this brief outline is based. In this approach meaning constructors are associated primarily with lexical items (though they can also be associated with phrase structure nodes in rules).

Meaning constructors have two parts: they are made up of a meaning on the left-hand side of the colon and a logical formula over semantic structures corresponding to that meaning on the right-hand side of the colon (semantic structures are related to f-structures by the projection $\sigma$ ). Consider as an example the meaning constructor associated with the lexical entry for yawned given in Dalrymple (2001: 233) and shown in (56).

$$
\begin{array}{r}
\text { yawned, } \mathrm{V}:(\uparrow \operatorname{PRED})={ }^{'} \mathrm{YAWN}<\mathrm{subj}> \\
\lambda X . \operatorname{yawn}(X):(\uparrow \mathrm{SUBJ})_{\sigma} \circ \uparrow_{\sigma}
\end{array}
$$

The meaning side of the constructor in (56) gives the meaning of yawn as one-place predicate (of course, other more complex meaning representations can be substituted for the predicate logic expressions used here, if desired). Meaning expressions are typed (so that the constant Kim, for example, is of type $e$ ): type information will determine how meaning expressions combine with others. The glue side uses linear implication: $(-\circ)$ is an implication which can be read as saying that if the meaning resource for the SUBJ is available then it can be consumed to produce the meaning of the sentence. ${ }^{28}$ Finally, it is standard practice to introduce labels as names of meaning constructors to ease reference to them, a practice we will adopt. Thus the meaning constructor for the individual Kim might be labelled as Kim:

\section{(57) Kim Kim: $\uparrow_{\sigma}$}

Dalrymple (200I) provides an analysis of the semantics of NP coordination which associates the semantic contribution g-and (group-forming and) in (58) with the coordinator and in its lexical entry (6o). In the meaning constructor, recall that the left-hand side is a meaning expression and the right-hand side is a glue constructor for resource-sensitive semantic construction using linear implication. On the meaning side, the lambda

[28] Along with linear implication, linear logic uses so-called multiplicative conjunction $(\otimes)$, a form of conjunction, and the 'of course' operator (!), which permits a premise to be used without being consumed, so that it is available for further deductions. 
expression denotes the group-forming function-here, a function from two individuals to the group containing those individuals. On the glue side, g-and consumes the semantics of one conjunct $(\uparrow \in)_{\sigma}$ and produces a function from the semantics of the other conjunct to the semantics of the coordinate structure as a whole. For more-than-binary coordination, a further semantic contribution g-and2, involving the ! ('of course') operator, can be used any number of times (including zero), each time adding an individual into the group (59). Since our primary focus here is on binary coordination, we will have no more to say about coordination involving multiple conjuncts.

$$
\begin{array}{ll}
\text { g-and } & \lambda X . \lambda Y .\{X, \mathrm{Y}\}: \\
& (\uparrow \in)_{\sigma<e>-}\left[(\uparrow \in)_{\sigma<e>}-\uparrow_{\sigma<e>}\right] \\
\text { g-and2 } & \lambda X . \lambda Y .\{X\} \cup Y: \\
& !\left[(\uparrow \in)_{\sigma<e>}-0\left[\uparrow_{\sigma<e>}{ }^{-} \uparrow_{\sigma<e>}\right]\right] \\
\text { and } \quad & (\uparrow \mathrm{CONJ})=\mathrm{AND} \\
& \text { [g-and] } \\
& \text { [g-and2] }
\end{array}
$$

Following Dalrymple (200I) and the arguments presented therein, we take NP coordination to be correctly characterised in this way as group formation. However, in the case of asyndetic coordination, there is no coordinator in the structure with which to associate the semantics of $\mathbf{g}$-and.

Notice also that in languages (such as these) with a three-way number distinction (singular, dual and plural), it is not possible simply to associate the use of the group-forming semantics with NUM resolution to PL, because the syntactic NUM of a group containing just a pair is DU. For present purposes, we restrict ourselves to binary coordination, and define the NUM resolution as in the template in (6I). This captures the generalisation that either the overall number is DU (i.e. when two singular nominals are coordinated), or (at least) one of the constituents is non-singular, in which case the overall number is PL. Note that since this makes reference to elements of the (coordinate) f-structure, rather that to c-structure daughters, NUM resolution will operate correctly in cases of discontinuous coordination as well as cases of contiguous coordination by simple juxtaposition.

$$
\begin{aligned}
& \text { BINARY: }\{(\uparrow \in \text { INDEX NUM }) \neq \mathrm{SG} \wedge(\uparrow \text { INDEX NUM })=\mathrm{PL}\} \\
& \mathrm{I}(\uparrow \text { INDEX NUM })=\text { DUAL }
\end{aligned}
$$

To complete the interpretation of nominal juxtapositions as coordinate, we need to associate the template BINARY and the meaning constructor g-and with the phrase structure rule in (55) (restricting our attention to cases of binary coordination). Since there is no coordinator, in asyndetic coordination we arbitrarily associate these with one of the daughter constituents. 
The phrase structure rule for juxtaposed NPs in coordination is therefore that in $(62){ }^{29}$

$$
\begin{aligned}
& X \rightarrow X \quad X \\
& \downarrow \in \uparrow \quad \downarrow \in \uparrow \\
& \text { @ } \text { NP-CNJT @ } @ \text { NP-CNJT } \\
& \text { (a)BINARY }
\end{aligned}
$$

\section{g-and}

Our analysis of juxtaposition with coordinate semantics is thus analogous to the analysis of (non-juxtaposed) coordinate constructions in other languages (Dalrymple and Kaplan 200I, Dalrymple 200I). In the next section we see how this same general approach can also provide an analysis of the Australian 'appositional' juxtapositions exemplified in section 2 above.

\subsection{Non-coordinate meanings of juxtaposition}

We have argued that the entire range of nominal juxtapositions all share the same basic f-structure. In the case of juxtapositions interpreted as close appositions, each constituent is associated with the NP-APPOS template, which ensures identity between the INDEX features of each constituent and the INDEX features of the set as a whole:

(63) NP-APPOS: $(\downarrow$ IND $)=(\uparrow$ IND $)$

(64) $X \rightarrow \quad X \quad X$

$$
\begin{array}{cc}
\downarrow \in \uparrow & \downarrow \in \uparrow \\
@ \text { NP-APPOS } & @ \text { NP-APPOS }
\end{array}
$$

As for the semantics of appositional juxtapositions such as (44), as a first approximation we take this to be basically intersective (applying to propertydenoting nominal (rather than NP) meanings). One way of doing this would be to propose a meaning constructor rather comparable to boolean and (as in the joint reading of five linguists and philosophers), taking two sets of properties and intersecting them (see Dalrymple 2004):

$$
\text { b-and } \quad \lambda X . \lambda Y . X \sqcap Y
$$

[29] In cases of discontinuous coordination, if neither part of the discontinuous structure is associated with the BINARY template and the g-and meaning constructor, meaning construction will fail, whereas if both parts are associated with these annotations, meaning construction will also fail because there will be unconsumed premises. Therefore nothing more needs to be added to ensure that only the right combination of meaning constructors and f-descriptions is selected. 
An alternative approach, which is the one we will follow here, is to model the semantics of close apposition on the semantics of nominal modification, as follows:

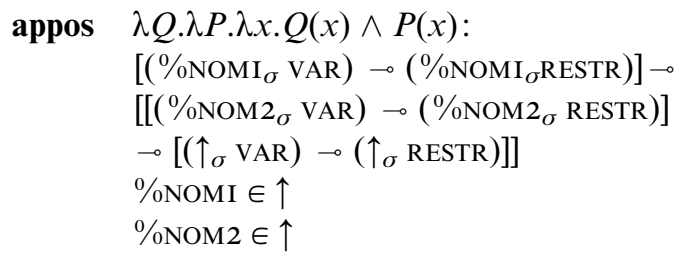

On the meaning side, this is a function which applies to two nominal $(<e, t\rangle)$ meanings and produces an abstraction over a logical conjunction of predications holding of the given individual (so it takes two nominal meanings and produces a nominal meaning, where nominal meanings are of type $\langle e, t>$ ). On the glue side, the meaning constructor consumes first one nominal contribution and then the other nominal contribution to produce the meaning of the structure as a whole. Note that the meaning which results from this process is a nominal meaning, that is a property or function of type $\langle e, t\rangle$, rather than a generalized quantifier or typical DP meaning. This meaning cannot of course be consumed directly by a verbal meaning constructor (given standard assumptions about the latter), but would need to be type-shifted (or the equivalent) to produce a full referential NP meaning. This is consistent with the fact that in these languages a bare nominal may be interpreted predicatively, but may also be interpreted as a full NP in appropriate context.

We can therefore complete our analysis of appositional juxtaposition by arbitrarily associating the appos semantics with some daughter in the appositional phrase structure rule:

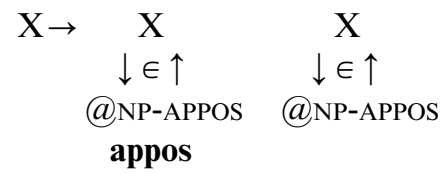

In order to see how this works, consider the nominal apposition in the nowfamiliar Wambaya example (I8). The semantics associated with each of the nominals in this construction is given in (68) and (69).

(68) garidi-ni (husband-ERG):

$\lambda X$.husband $(X):\left(\uparrow_{\sigma} \operatorname{VAR}\right) \multimap\left(\uparrow_{\sigma} \operatorname{RESTR}\right)$

(69) bungmanyi-ni (old.man-ERG):

$\lambda X$.old.man $(X):\left(\uparrow_{\sigma} \mathrm{VAR}\right) \multimap\left(\uparrow_{\sigma} \mathrm{RESTR}\right)$ 
The meaning constructor (66), associated with the appositional use of the juxtaposition schema, consumes (68) and (69) to produce another nominal meaning, as follows:

$$
\begin{aligned}
& \text { garidi-ni bungmanyi-ni (husband-ERG old.man-ERG): } \\
& \lambda X \text {.old.man }(X) \wedge \text { husband }(X): \\
& \left(\uparrow_{\sigma} \mathrm{VAR}\right) \multimap\left(\uparrow_{\sigma} \text { RESTR }\right)
\end{aligned}
$$

Note that in these languages, a bare nominal such as (68) or (69) (or indeed (70)) may be interpereted predicatively, but may also be given a range of referential (or entity-denoting) NP meanings in context (e.g. 'the old man', 'an old man', 'old men'). Pronouns and demonstratives may accompany the nominal in 'determinizing' function but are by no means obligatory in the production of full (referential) NP meanings. In the latter cases, where there are no demonstratives or pronouns, we take it that additional meaning constructors (not associated with lexical material) must be available to lift nominals into the appropriate range of NP meanings. ${ }^{30}$

Other construction types expressed by means of juxtaposition and discussed in section 2, such as generic-specific and part-whole constructions, can also be straightforwardly accounted for by the approach suggested in this paper, although there is certainly more to be said on the details of their semantic analysis. These constructions are likewise licensed by the non-coordinate phrase structure rule (67), which is fully consistent with the consensus view in the Australianist tradition that treats such constructions as consisting of apposed nominals (e.g. Heath 1978, Blake 1987, Evans I995, etc.).

The f-structure corresponding to the juxtaposed (generic-specific) construction in (7I) $(=(\mathrm{II}))$ is given in (72).

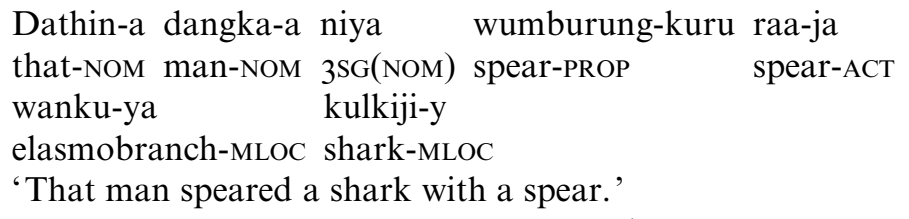

(Evans 1995: 244 Kayardild)

[30] Of course, our account of the (various) semantics associated with nominal juxtaposition per se would also have to be extended to deal with examples such as (i), in which it appears that full NPs (i.e. of type $e$ ) are juxtaposed.

(i) Ngada bala-thu niwan-ju naljirndirri-wu, marrwa-wu niya rabi-ju ISG(NOM) hit-POT him-MPROP scrub turkey-MPROP near-MPROP 3 SG(NOM) get.up-POT 'I'll shoot him, the scrub turkey, he'll fly up nearby.'

(Evans 1995: 239 Kayardild)

Such data raise many interesting issues which we leave for further research. In the case of (i), however, it is possible that what we have is in any case an instance of loose (non-restrictive) apposition, as perhaps suggested by the translation offered by Evans. 
(72)

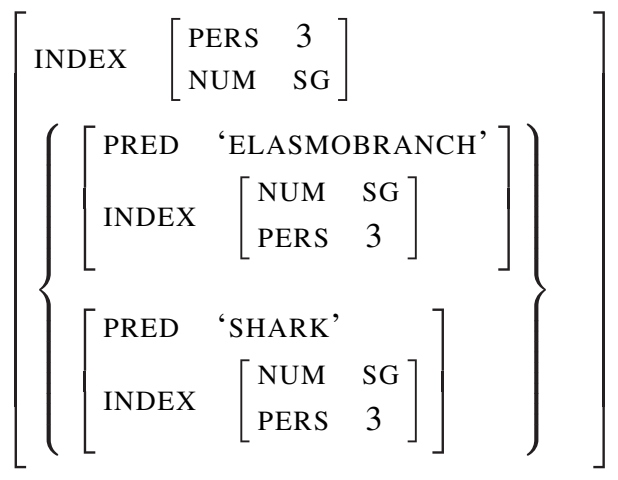

Standard (nominal) meaning constructors along the lines of (68) are given for wanku-ya (elasmobranch-MLOC) and kulkiji-y (shark-MLOC) in (73) and (74). These combine with the appositional meaning constructor to yield (75):

(73) wanku-ya (elasmobranch.MLoc): $\lambda x . e l a s m o b r a n c h(x):\left(\uparrow_{\sigma} \operatorname{VAR}\right) \rightarrow\left(\uparrow_{\sigma} \operatorname{RESTR}\right)$

(74) kulkiji-y (shark.MLOC): $\lambda x \cdot \operatorname{shark}(x):\left(\uparrow_{\sigma}\right.$ VAR $) \multimap\left(\uparrow_{\sigma}\right.$ RESTR)

(75) wanku-ya kulkiji-y (elasmobranch-MLOC shark-MLOC): $\lambda X$.elasmobranch $-f i s h(X) \wedge \operatorname{shark}(X):\left(\uparrow_{\sigma} \mathrm{VAR}\right) \multimap\left(\uparrow_{\sigma} \mathrm{RESTR}\right)$

In the case of generic-specific constructions, there is an additional relationship between the properties that the nominal predicates introduce, in that one of the nominals (the 'generic' term) is (typically) a hypernym whose denotation properly includes that of the other ('specific') term. We abstract away from this here, but assume that this further semantic restriction on the construction could be captured by an additional meaning postulate specifying that an appropriate relationship must hold between the two nominal restrictor properties.

\section{TEMPLATIC MISMATCH: INCLUSORY CONSTRUCTIONS}

Above we have argued that the range of juxtaposed nominal constructions that we find in many Australian languages - including coordination, close apposition, generic-specific constructions, part-whole constructions and nominal-pronoun combinations - can be accounted for with a modular approach in which these constructions have the same surface syntactic structure as f-structure sets, with the differences resulting from feature resolution or identity, and in the mapping to the semantics. We have proposed a single basic phrase structure rule (76), and two alternative sets of annotations (specifying functional equations and meaning constructors) corresponding 
to coordinate constructions and non-coordinate constructions respectively, as laid out in (77).

(76) $X \rightarrow X \quad X$

$$
\downarrow \in \uparrow \quad \downarrow \in \uparrow
$$

(77) (a) Annotate each daughter@NP-CNJT and some daughter@BINARY and g-and; OR

(b) Annotate each daughter @NP-APPOs and some daughter appos

These sets of annotations ensure that the coordinated constructions involve feature resolution and a coordinate semantics, while the noncoordinated constructions involve feature identity between the set and its members, and a close appositional semantics.

However, the existence of a single 'coordinate' phrase structure rule and two different templates governing the interaction between the INDEX features of the set and its members allows for the possibility that there may be a mismatch between the templates associated with each constituent of the 'coordinated' phrase. In other words, it is possible for one constituent to be associated with the NP-CNJT template and the other with the NP-APPOS template. In this section we show that this possibility is, in fact, exactly what we find in inclusory constructions. ${ }^{31}$

As already discussed in section 2 above, the inclusory construction is another type of nominal juxtaposition structure common to many Australian languages. An inclusory construction typically involves two juxtaposed elements, one a pronominal referring to the group as a whole and the other a (pro)nominal picking out a subset of the group. Examples include the following:

Tjirlpi-lu nyupali kati-ku-nti

old.man-ERG.NAME 2DU.ERG take-FUT-MAYBE

'You and the Old Bloke might take (us).' (lit. 'you two, including the Old Bloke, might take (us)')

(79) Nga-rr-a kajakaja warra-ja thaa-th

I-DU-NOM daddy(NOM) go-ACT return-ACT

'Daddy and I will go' (lit. 'we two, including daddy, will go')

(Evans I995: 249 Kayardild)

Inclusory constructions (also called 'plural pronoun constructions' in the literature) are found in languages from many different families (Schwartz I988a, b; McNally I993; Lichtenberk 2000; Bril 2004), and are described for

[3I] As noted above, this may also suggest an approach to feature mismatch in some part-whole constructions, such as 'woman feet'. 
Australian languages in Singer (200I, 2005) ${ }^{32}$ The correct analysis of the inclusory construction has been the source of some debate in the literature. Schwartz $(1988 \mathrm{a}, \mathrm{b})$ analyses the inclusory construction as deriving from a coordination construction, as do Hale (I966, I973) and Nash (1986) in their analysis of inclusory constructions in the Australian language Warlpiri. Singer (200I), on the other hand, argues that the inclusory construction in Australian languages is a distinct construction type, albeit similar in some respects to coordination constructions, based on the fact that the inclusory construction is an endocentric construction with the features of one of the elements (i.e. the superset pronominal) being identical to the features of the whole argument. This is shown most clearly in a language with verbal agreement, as in example (80) from Nunggubuyu:

(80) nurru = wang ma:gurn nurru

we.EX.PL $=$ killed.it Magurn we.EX.PL

'Magurn and us killed it (buffalo).'

(Heath 1984: 542 Nunggubuyu)

In terms of their surface syntax, (Type I) inclusory constructions generally consist of two juxtaposed nominal elements, and are therefore syntactically similar to the other juxtaposed constructions we have discussed above. Indeed, many language descriptions treat them as a type of 'appositional' construction similar to part-whole and/or generic-specific constructions (e.g. Dench 1995, Evans 1995, among others). We therefore propose that they should likewise be analysed as sets at f-structure, therebycapturing their syntactic similarity with apposition and coordination constructions.

Inclusory constructions are a particularly interesting case, as the features of the set overall are identical to the features of one member of the set (the pronominal), in which the features of the other member must be included. Thus, inclusory constructions are a composite of the coordination and appositional schemas presented in (62) and (67) above. The constituent corresponding to the superset pronominal carries the appositional template

[32] There are actually two types of inclusory constructions. The first, exemplified here, involves two juxtaposed NP elements. The second involves a verb-coded superset pronoun and just one NP element, as in example (i) below. Singer (200I) refers to these as Type I and Type 2, respectively.

(i) nyari-bu-ydhi-ni rni-yul-pula IDU.EX-hit-RECIP-P.CON M.SG-Aboriginal-DU

'I and a [Aboriginal] man were fighting.'

(Heath 1978: 29I Ngandi)

Our focus here is on Type I inclusory constructions, since they involve the juxtaposition of two nominal elements. However, our analysis of Type I inclusory constructions can be extended to Type 2 through the association of the properties of the superset pronominal with the verbal agreement morphology, including the specification that the features of the verb-inflected pronominal be equal to the features of the set. For reasons of space, however, we leave exemplification of this extension of the analysis for future work. 
(specifying that its INDEX features are identical to the index features of the whole) and the constituent corresponding to the subset member carries the coordination template (specifying that its INDEX features must be a subset of the INDEX features of the whole) ${ }^{33}$

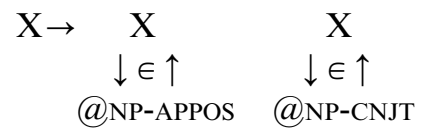

$$
\begin{aligned}
& {\left[\begin{array}{c}
{\left[\begin{array}{l}
{\left[\begin{array}{ll}
\text { PRED } & \text { 'DADDY' } \\
\text { INDEX } & {\left[\begin{array}{ll}
\text { NUM } & \text { SG } \\
\text { PERS } & 3
\end{array}\right]}
\end{array}\right]} \\
{\left[\begin{array}{ll}
\text { PRED } & \text { 'PRO' } \\
\text { INDEX } & {\left[\begin{array}{ll}
\text { NUM } & \text { DUAL } \\
\text { PERS } & 1
\end{array}\right]}
\end{array}\right]}
\end{array}\right\}}
\end{array}\right.}
\end{aligned}
$$

Thus, our analysis of nominal juxtaposition in Australian languages extends directly to inclusory constructions, correctly capturing the fact that these various juxtaposed construction types are syntactically similar in many Australian languages. ${ }^{34}$ Moreover, this analysis captures the various characteristics of the inclusory construction discussed in the literature. The fact that inclusory constructions are similar to coordination constructions is captured by the fact that, like coordination constructions, inclusory constructions are represented as sets at f-structure. The endocentricity of the inclusory construction (Singer 200I), namely the fact that the features of the whole argument are identical to those of the superset pronominal, is captured by having the pronominal carry the NP-APPOS template, which specifies that the features of the individual member are carried up to the set as a whole. The inclusory nature of the construction is captured by the fact that the other element must have features which form a subset of the features of the entire set. ${ }^{35}$

[33] This phrase structure rule is written so as to allow either ordering of the two elements (as indicated by the comma between the two NPs). However, in some languages it may be necessary to fix the ordering of the two elements in the case of inclusory constructions.

[34] The semantics of the inclusory is that one member of the set denotes a group and the other member contributes a further restriction over the group by providing a specification about one of its members. We leave detailed discussion of the semantics of the inclusory for future research.

[35] Note that, even in languages in which the two elements can appear in either order, the nature of the templates will ensure that the NP-APPOS template is associated with the superset 
Treating inclusory constructions as sets at f-structure is further supported by the fact that in some Australian languages they can be marked with suffixes that explicitly indicate set membership. In Yidiny the 'one of a group' suffix $-b a$ is used in both coordination constructions (83) and inclusory constructions (84):

$\begin{array}{lll}\text { Darnggidarnggiba } & \text { yaburruba } & \text { galing } \\ \text { old.woman:ba(ABS) } & \text { young.girl:ba(ABS) } & \text { go:PRES }\end{array}$

'An old woman (being one of a group of people) and a girl (being another member of a group) are going.'

(Dixon 1977: 177 Yidiny)

(84) Nganytyi bunya:ba galing

1 NON-SING woman: $b a$ go:PRES

'A woman and I (and some others) are going.'

(Dixon 1977: 178 Yidiny)

Thus, our analysis of juxtaposition and asyndetic coordination in Australian languages extends naturally to inclusory constructions as well, capturing the similarities amongst these construction types and providing a unified analysis of the NP juxtaposition that is so prevalent in these languages.

\section{CONCLUSION AND FURTHER IMPLICATIONS}

We have shown how the range of juxtaposed NP constructions in Australian languages can be accounted for relatively straightforwardly within the constraint-based lexicalist formalism of LFG. We have developed an account in which nominal-nominal sequences all have essentially the same f-structure, but correspond to three different feature association patterns, as in (85)-(87), and map onto a range of different semantics correlated with these three different patterns. In the case of coordinate constructions, the INDEX features of the elements in the set-valued f-structure stand in a subset relation to the INDEX of the set itself. In the case of appositional constructions, the INDEX features of the individual elements are equivalent, and are also equivalent to those of the set itself. Inclusory constructions involve a hybrid of the two, whereby one element of the set has the same INDEX features as the set itself, while the other element in the set stands in a subset relation to the overall INDEX.

pronominal and the coordination template with the subset (pro)nominal. This is because, were the associations to be reversed and the coordination template to be associated with the superset pronominal, its features would not be a subset of the features of the entire set (which would be the features of the subset (pro)nominal in this case). 
(85)

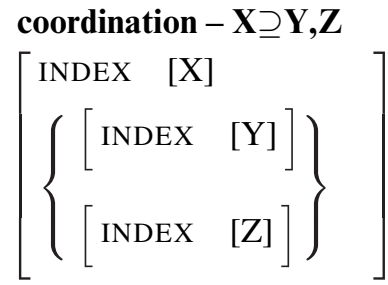

(86) apposition $-\mathbf{X}=\mathbf{Y}=\mathbf{Z}$

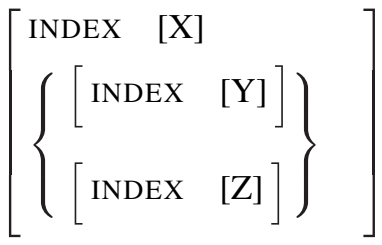

$$
\begin{aligned}
& \text { inclusory }-\mathbf{X}=\mathbf{Y} \supseteq \mathbf{Z} \\
& {\left[\begin{array}{l}
{\left[\begin{array}{ll}
\operatorname{INDEX} & {[\mathrm{Y}]}
\end{array}\right]} \\
{\left[\begin{array}{ll}
\operatorname{INDEX} & {[\mathrm{Z}]}
\end{array}\right]}
\end{array}\right\}}
\end{aligned}
$$

The flexible architecture of LFG thus provides a unified syntactic account of a range of juxtaposed nominal constructions common in Australian languages, while still capturing their semantic differences. In this paper we have shown how the use of hybrid f-structures can be extended beyond true (semantically) coordinated constructions to generic-specific, part-whole and other types of close appositional constructions, making a distinction between syntactic coordination (hybrid structures) and semantic coordination (corresponding to feature resolution and coordinate semantics) in a simple and intuitive way.

One of the implications of our analysis of Australian juxtaposed nominal constructions is that close appositions are structurally the same as coordinations in the syntax of these languages, which in turn raises the possibility that this might be true of close appositions and coordination in (some) other languages. A further implication of our general approach is that we may expect to find a structural relationship between non-asyndetic coordination and appositional constructions also. In other words, do we find non-asyndetic coordinated structures which can similarly be used with an appositional semantics? In fact, boolean coordination in languages like English may well fit into a continuum between coordination and close apposition in this way. The conjunction of singular nominals generally forms a plural noun phrase in English, under (some form of) group-forming coordination as discussed in section 3 , but this is not always the case. As the SG 
verb agreement in example (88) indicates, 'vice-president' and 'presidentelect' refer here to the same individual. This boolean or joint reading is in contrast to (89), which involves a split or group-forming reading.

(88) The vice-president and president-elect is eating pizza.

(King \& Dalrymple 2004: 75)

(89) The vice-president and president-elect are eating pizza.

As King \& Dalrymple (2004) show (see also Heycock \& Zamparelli I999, 2000) languages differ in the distribution of these readings. Languages such as English permit both joint and split readings (with singular nouns) under a single determiner such as the or this, while other languages permit only joint readings in these circumstances (such as Italian, Portuguese and German). The German example in (90), for instance, has only a joint reading.

(90) mein bester Freund und Mann my.M.SG best friend.M.SG and husband.M.SG 'my best friend and husband'

(King \& Dalrymple 2004: 93 German)

The distinction between split and joint readings is most evident with singular conjuncts, but is also relevant for the interpretation of coordinate structures with plural conjuncts, as in five philosophers and linguists, which has a number of interpretations including the joint reading under which each individual (of five) is both a linguist and a philosopher.

King \& Dalrymple (2004) propose that the distinction between split and joint readings involves two different semantics for and, boolean-and and group-and. Group-forming and ('normal' coordination) simply requires a plural INDEX, but King \& Dalrymple propose that boolean-and is associated with the syntactic INDEX requirement stated in (9I), ${ }^{36}$ which is very similar in effect to the INDEX constraint used in this paper for the cases of appositional juxtaposition.

\section{(9I) boolean and $(\uparrow \operatorname{INDEX~NUM~})=(\uparrow \in$ INDEX NUM $)$}

It is sometimes suggested that a proper account of nominal coordination should involve just one unitary semantics, either in terms of group forming or of boolean coordination (for example, Heycock \& Zamparelli (2000) propose one underlying semantics for and and associate different (semantic) procedures with various (abstract) syntactic features in English and Italian NPs). Similarly, the use of the conjunctive coordinator and to conjoin alternative descriptions of a single individual might seem idiosyncratic. However, our proposal provides support for the existence of both groupforming and boolean and in nominal coordination, by placing the existence

[36] Additionally there is a semantic requirement (unformulated here) which requires all conjuncts to have the same number. 
of boolean coordination (that is, the joint reading of my friend and colleague) in a rather different crosslinguistic context. We have argued that appositions, inclusories and (standard) conjunctions may all be associated with precisely the same syntactic device, namely of asyndetic coordination or juxtaposition. On our view, then, boolean coordination can be considered to be essentially similar to the (close) appositional juxtapositions we have discussed in Australian languages, the only difference being the presence of an overt coordinator in the former (and note that in English, overt conjunctions, particularly or, may occur in appositions). Boolean coordination is thus syntactically coordinated (having a hybrid f-structure), but semantically appositional (having no feature resolution and appositional (i.e. boolean) semantics).

\section{REFERENCES}

Acuña-Fariña \& Juan Carlos. 1999. On apposition. English Language and Linguistics 3.I, 59-8I. Arnold, Doug. 2004. Non-restrictive relative clauses in construction-based HPSG. In Stefan Müller (ed.), HPSGo4, 27-47. Stanford, CA: CSLI Publications. http://csli-publications. stanford.edu/HPSG/5/arnold.pdf (Io July 2009).

Arnold, Doug. 2007. Non-restrictive relatives are not orphans. Journal of Linguistics 43.2, 27I-309.

Austin, Peter. 1981. A grammar of Diyari, South Australia. Cambridge: Cambridge University Press.

Austin, Peter. 200I. Word order in a free word order language: The case of Jiwarli. In Simpson et al. (eds.), 305-323.

Austin, Peter \& Joan Bresnan. 1996. Non-configurationality in Australian Aboriginal languages. Natural Language \& Linguistic Theory I4.2, 21 5-268.

Blake, Barry J. 1979. A Kalkatungu grammar. Canberra: Pacific Linguistics.

Blake, Barry J. 1983. Structure and word order in Kalkatungu: The anatomy of a flat language. Australian Journal of Linguistics 3.2, I43-175.

Blake, Barry J. 1987. Australian Aboriginal grammar. London: Croom Helm.

Blake, Barry J. 200I. The noun phrase in Australian languages. In Simpson et al. (eds.), 4I5-425.

Bresnan, Joan. 200I. Lexical Functional Syntax. Oxford: Blackwell.

Bril, Isabelle. 2004. Coordination strategies and inclusory constructions in New Caledonian and other Oceanic languages. In Haspelmath (ed.), 499-533.

Butt, Miriam \& Tracy Holloway King (eds.). 2004. LFG'04. Stanford, CA: CSLI Publications. http://cslipublications.stanford.edu/LFG/9/lfgo4.html (Io July 2009).

Crystal, David. 1997. A dictionary of linguistics and phonetics. Oxford: Blackwell.

Dalrymple, Mary. 200I. Lexical Functional Grammar. San Diego, CA: Academic Press.

Dalrymple, Mary. 2004. Noun coordination: Syntax and semantics. Presented at the University of Canterbury, New Zealand.

Dalrymple, Mary, Helge Dyvik \& Louisa Sadler. 2007. Gender resolution and gender indeterminacy. Presented at LFG Conference 2007, Stanford.

Dalrymple, Mary \& Ronald M. Kaplan. 2000. Feature indeterminacy and feature resolution. Language 76.4, 759-798.

Dalrymple, Mary, Ronald M. Kaplan \& Tracy Holloway King. 2004. Linguistic generalizations over descriptions. In Butt \& King (eds.), 199-208. http://csli-publications.stanford.edu/LFG/ 9/lfgo4dkk.pdf (Io July 2009).

Dalrymple, Mary, Ronald M. Kaplan, John T. Maxwell, III \& Annie Zaenen (eds.). 1995. Formal issues in Lexical-Functional Grammar. Stanford, CA: CSLI Publications.

Dench, Alan. 1995. Martuthunira: A language of the Pilbara Region of Western Australia. Canberra: Pacific Linguistics.

Dixon, R. M. W. 1977. A grammar of Yidiny. Cambridge: Cambridge University Press. 
Dixon, R. M. W. 2002. Australian languages: Their nature and development. Cambridge: Cambridge University Press.

Espinal, Maria Teresa. I99I. The representation of disjunct constituents. Language 67, 726-762.

Evans, Nicholas. 1995. A grammar of Kayardild: With historical-comparative notes on Tangkic. Berlin: Mouton de Gruyter.

Fabb, Nigel. 1990. The difference between English restrictive and non-restrictive relative clauses. Journal of Linguistics 26.I, 57-78.

Falk, Yehuda. 200I. Lexical-Functional Grammar: An introduction to Parallel Constraint-Based Syntax. Stanford, CA: CSLI Publications.

Gaby, Alice. 2006. A grammar of Kuuk Thaayorre. Ph.D. dissertation, University of Melbourne.

Goddard, Clifford. 1985. A grammar of Yankunytjatjara. Alice Springs: Institute for Aboriginal Development.

Hale, Kenneth L. I966. Kinship reflections in syntax. Word 22, 318-324.

Hale, Kenneth L. I973. Person marking in Warlbiri. In Stephen R. Anderson \& Paul Kiparsky (eds.), A Festschrift for Morris Halle, 308-344. New York: Holt, Rinehard and Winston.

Hale, Kenneth L. 1981. On the position of Warlpiri in a typology of the base. Bloomington, IN: Distributed by Indiana University Linguistics Club.

Hale, Kenneth L. 1983. Warlpiri and the grammar of non-configurational languages. Natural Language \& Linguistic Theory I.I, 5-47.

Haspelmath, Martin. 2004. Coordinating constructions: An overview. In Haspelmath (ed.), 3-40.

Haspelmath, Martin (ed.) 2004a. Coordinating constructions. Amsterdam: John Benjamins.

Haspelmath, Martin. 2007. Coordination. In Timothy Shopen (ed.), Language typology and syntactic description, vol. II: Complex constructions, 2nd edn., I-5I. Cambridge: Cambridge University Press.

Heath, Jeffrey. 1978. Ngandi grammar, texts and dictionary. Canberra: Pacific Linguistics.

Heath, Jeffrey. 1984. Functional grammar of Nunggubuyu. Canberra: AIAS.

Heycock, Caroline \& Roberto Zamparelli. 1999. Toward a unified analysis of DP conjunction. In Paul Dekker (ed.), The Twelfth Amsterdam Colloquium, I27-I32. Amsterdam: The Institute for Logic, Language and Computation (ILLC), University of Amsterdam.

Heycock, Caroline \& Roberto Zamparelli. 2000. Friends and colleagues: Plurality and NP-coordination. In Masako Hirotani, Andries Coetzee, Nancy Hall \& Ji-Yung Kim (eds.), 3oth Annual Meeting of the North Eastern Linguistic Society (NELS 30) 34I-352. Amherst, MA: Graduate Linguistic Student Association (GLSA).

Jackendoff, Ray S. 1977. X-bar syntax: A study of phrase structure. Cambridge, MA: MIT Press. Johannessen, Janne Bondi. 1998. Coordination. Oxford: Oxford University Press.

Kaplan, Ronald M. \& John T. Maxwell, III. I988. Constituent coordination in LexicalFunctional Grammar. I2th International Conference on Computational Linguistics (COLING 88), vol. I, 303-305. Budapest: Association for Computational Linguistics. [Reprinted in Dalrymple et al. (eds.), I995, I99-210.]

Keizer, Evelien. 2005. The discourse function of close appositions. Neophilologus 89, 447-467.

Keizer, Evelien. 2007. The English noun phrase. Cambridge: Cambridge University Press.

Kempson, Ruth. 2003. Nonrestrictive relatives and growth of logical form. 22nd West Coast Conference on Formal Linguistics (WCCFL 22), 30I-3I4.

King, Tracy Holloway \& Mary Dalrymple. 2004. Determiner agreement and noun conjunction. Journal of Linguistics 40.I, 69-104.

Lekakou, Marika \& Kriszta Szendröi. 2007. Eliding the noun in close apposition, or Greek polydefinites revisited. In Richard Breheny \& Nikolaos Velegrakis (ed.), UCL Working Papers in Linguistics I9, I29-I54. London: University College London.

Lichtenberk, Frantisek. 2000. Inclusory pronominals. Oceanic Linguistics 39.I, I-32.

McNally, Louise. 1993. Comitative coordination: A case study in group formation. Natural Language \& Linguistic Theory II, 347-79.

Meyer, Charles F. 1992. Apposition in contemporary English. Cambridge: Cambridge University Press.

Nash, David. 1986. Topics in Warlpiri grammar. Ph.D. dissertation, MIT.

Nordlinger, Rachel. I998a. A grammar of Wambaya, Northern Territory (Australia). Canberra: Pacific Linguistics. 


\section{LOUISA SADLER \& RACHEL NORDLINGER}

Nordlinger, Rachel. 1998b. Constructive case: Evidence from Australian languages. Stanford, CA: CSLI Publications.

Pensalfini, Robert. 2003. A grammar of Jingulu: An Aboriginal language of the Northern Territory. Canberra: Pacific Linguistics.

Peterson, Peter. 2004. Non-restrictive relatives and other non-syntagmatic relations in an LF framework. In Butt \& King (eds.), 39I-397. http://csli-publications.stanford.edu/LFG/9/ lfgo4peterson.pdf (Io July 2009).

Potts, Christopher. 2003. The logic of conventional implicatures. Ph.D. dissertation, University of California, Santa Cruz.

Potts, Christopher. 2005. The logic of conventional implicatures. New York: Oxford University Press.

Progovac, Ljiljiana. 1997. Slavic and the structure for coordination. In Martina Lindseth \& Steven Franks (eds.), Formal Approaches to Slavic Linguistics: The Indiana Meeting I996, 207-224. Ann Arbor, MI: Michigan Slavic Publications.

Quirk, Randolph, Sidney Greenbaum, Geoffrey Leech \& Jan Svartvik. 1985. A comprehensive grammar of the English language. London: Longman.

Schwartz, Linda. I988a. Asymmetric feature distribution in pronominal 'coordinations'. In Michael Barlow \& Charles A. Ferguson (eds.), Agreement in natural language, 237-250. Stanford, CA: CSLI Publications.

Schwartz, Linda. I988b. Conditions for verb-coded coordination. In Michael Hammond, Edith Moravcsik \& Jessica Wirth (eds.), Studies in syntactic typology, 53-73. Amsterdam: John Benjamins.

Sharp, Janet. 2004. Nyangumarta: A language of the Pilbara Region of Western Australia. Canberra: Pacific Linguistics.

Simpson, Jane. I99I. Warlpiri morphosyntax: A lexicalist approach (Studies in Natural Language and Linguistic Theory 23). Dordrecht: Kluwer.

Simpson, Jane \& Joan Bresnan. 1983. Control and obviation in Warlpiri. Natural Language \& Linguistic Theory I, 49-64.

Simpson, Jane, David Nash, Mary Laughren, Peter Austin \& Barry Alpher (eds.). $200 I$. Forty ears on: Ken Hale and Australian languages. Canberra: Pacific Linguistics.

Singer, Ruth. 200I. The inclusory construction in Australian languages. Honours thesis, University of Melbourne.

Singer, Ruth. 2005. Comparing constructions across languages: A case study of the relationship between the inclusory construction and some related nominal constructions. Presented at Association for Linguistic Typology conference ALT VI, Padang, Indonesia, July 2005.

Stirling, Lesley. 2008. 'Double reference' in Kala Lagaw Ya narratives. In Ilana Mushin \& Brett Baker (ed.), Discourse and grammar in Australian languages, 167-202. Amsterdam: John Benjamins.

Vries, Mark de. 2006. The syntax of appositive relativization: On specifying coordination, free relatives and promotion. Linguistic Inquiry 37, 229-270.

Wechsler, Stephen \& Larisa Zlatić. 2003. The many faces of agreement. Stanford, CA: CSLI Publications.

Wilkins, David P. 2000. Ant, ancestors and medicine: A semantic and pragmatic account of classifier constructions in Arrernte (Central Australia). In Gunter Senft (ed.), Systems of nominal classification, I47-216. Cambridge: Cambridge University Press.

Wilson, Stephen. 1999. Coverbs and complex predicates in Wagiman. Stanford, CA: CSLI Publications.

Authors' addresses : (Sadler)

Department of Language and Linguistics, University of Essex,

Wivenhoe Park, Colchester $\mathrm{CO}_{4} 3 \mathrm{SQ}$, UK

louisa@essex.ac.uk

(Nordlinger)

School of Languages and Linguistics, Arts Centre Building,

The University of Melbourne, Parkville, Victoria 30Io, Australia

racheln@unimelb.edu.au 